\title{
Intradermal Micro-Dosing of AbobotulinumtoxinA for Face-Lifting: How Long Does It Last?
}

\author{
Rungsima Wanitphakdeedecha (i) - Chadakan Yan - Chalermkwan Apinuntham • \\ Viboon Rojanavanich • Kathryn Anne G. Cembrano · Sasima Eimpunth • \\ Woraphong Manuskiatti
}

Received: May 17, 2020 / Published online: June 26, 2020

(C) The Author(s) 2020

\section{ABSTRACT}

Introduction: Intradermal injection of botulinum toxin type A (BoNT/A) has been used offlabel by many clinicians for face-lifting. Previous studies on abobotulinumtoxinA (ABO) (Dysport ${ }^{\circledR}$; Ipsen Biopharm Ltd.) have demonstrated clinical efficacy in face-lifting when compared to normal saline solution (NSS). However, few clinical studies have evaluated $\mathrm{ABO}$ in terms of duration of sustained effects for face-lifting.

Methods: Thirty subjects were enrolled, and their face was injected with $\mathrm{ABO}$ at a dilution of 1 vial: $7 \mathrm{~mL}$ (500 $\mathrm{U}$ in $7 \mathrm{~mL}$ of NSS) using an intradermal injection technique. Standardized photographic documentation was obtained using a two-, and three-dimensional imaging system (Vectra H1, Canfield Scientific, Inc, Fairfield, NJ) at baseline, immediately after injection, 2 weeks after injection and at $1,2,3$,

Digital Features To view digital features for this article go to https://doi.org/10.6084/m9.figshare.12482006.

R. Wanitphakdeedecha $(\bowtie) \cdot$ C. Yan

C. Apinuntham - K. A. G. Cembrano - S. Eimpunth

. W. Manuskiatti

Department of Dermatology, Faculty of Medicine

Siriraj Hospital, Mahidol University, Bangkok,

Thailand

e-mail: rungsima.wan@mahidol.ac.th

V. Rojanavanich

Bangkok Christian Hospital, Bangkok, Thailand
4,5 and 6 months of follow-up after treatment. The face-lifting effects were graded by both the subjects and two blinded dermatologists who compared photographs taken at the different time points. Side effects were also recorded at the end of the study.

Results: Of the 30 subjects, 28 completed treatment and attended every follow-up visit. All subjects were female with Fitzpatrick skin type II to IV. The average age of the subjects was $27.6 \pm 3.4$ (range $22-34$ ) years. The total number of $\mathrm{ABO}$ units used varied for each subject (range 200-250 U), with the average ( \pm standard deviation) dose being $237 \pm 19$ units. Most of the subjects reported significant face-lifting up to 3 months post-procedure. However, facelifting assessed by blinded dermatologists was notably lower than that of each patient's evaluation. The difference in the facial contouring volume of the nasolabial fold and jawline, as measured by the Vectra $\mathrm{H} 1$ imaging system, was statistically significant from baseline up until 3 months after injection $(p=0.001$ and $p=0.001$, respectively). The only side effect found in this study was minimal bruising, which was seen in $13.8 \%$ of subjects. None of the subjects reported facial asymmetry, either at rest or during facial expression.

Conclusion: The results of this study demonstrate the face-lifting effect of $\mathrm{ABO}$ intradermal injection. The results show sustained effects up to 3 months after injection. 
Keywords: AbobotulinumtoxinA; Face-lifting; Intradermal injection; Long-term; Micro-dosing

\section{Key Summary Points}

\section{Why carry out this study?}

Previous studies have demonstrated clinical efficacy of AbobotulinumtoxinA (ABO) in face-lifting compared to normal saline solution (NSS).

To date, no clinical studies have evaluated the duration of the sustained effects of $\mathrm{ABO}$ for this indication.

\section{What was learned from the study?}

The intradermal injection technique using $\mathrm{ABO}$ at a dilution of 1 vial:7 mL NSS provided significant sustained face-lifting effects up to 3 months post-treatment.

Efficacy of the technique is highly dependent on the skill of the aesthetic practitioner injecting, the appropriate dilution and patient selection.

\section{INTRODUCTION}

Botulinum toxin A (BoNT/A) has been approved for aesthetic purposes in the field of dermatology since 2002 [1], but was first reported to reduce the appearance of facial wrinkles in 1990 by Carruthers and Carruthers [2]. Its mechanism of action involves inhibition of acetylcholine release at the neuromuscular junction, thereby producing the end result of muscle relaxation. Due to their soft-tissue attachments, facial muscles pull across skin to produce facial expressions. Thus, by targeting these muscle groups, aesthetic practitioners can address dynamic frown lines [1]. However, the efficacy and good safety profile of BoNT/A has led to expansion of its applications to include facial contouring, facial asymmetry correction and even rejuvenation [2].
The off-label use of BoNT/A in a variety of cosmetic procedures has become more popular in recent years [3]. One of the most common off-label uses in aesthetic practice is the intradermal BoNT/A injection technique, which has been shown to provide benefits in terms of improving skin texture and face-lifting $[4,5]$. The intradermal or subdermal injection technique, otherwise known as "micro-dosing", involves the use of a lower concentration of BoNT/A than the traditional formulation for intramuscular injection technique, which is injected in multiple tiny aliquots over the areas that lifting is needed $[6,7]$.

It has been suggested that in terms of the treatment of facial wrinkles, there is no difference in the duration of the anti-wrinkle effects of BoNT/A and intradermal and intramuscular injection [8]. With the traditional intramuscular technique, immediate clinical effects are usually observed within 1-4 days following treatment, with peak effects seen at 1-4 weeks post-procedure $[1,2]$. Differences between individuals in the duration of the effect have been reported following dose requirement variations but, on average, effects are seen for up to 60-120 days [1, 2]. Intradermal BoNT/A injection for face-lifting has been used by many clinicians, especially in the Asian population. There have been claims that the duration of the face-lifting effect with intradermal BoNT/A injection is shorter than that of the conventional intramuscular injection for facial wrinkles [9]. In addition, intradermal injection is associated with more pain [9]. Several studies conducted on the intradermal technique have reported varying durations of effects, ranging from 3 to 6 months; however, most of these studies were focused on other parameters of rejuvenation, such as facial elasticity, texture, pore size or sebum production [5, 9-11].

In a previous study on abobotulinumtoxinA $(\mathrm{ABO})$ we demonstrated its clinical efficacy in face-lifting as compared to normal saline solution (NSS) [12]. However, the study protocol was designed to follow the subjects only up to 2 weeks after treatment at which time the facelifting effect was evaluated. Since it was a splitface comparison study, most of the subjects received $\mathrm{ABO}$ on the control side at the 2 -week 
follow-up visit. Therefore, the objective of this study was to determine the efficacy and duration of sustained effects of $\mathrm{ABO}$ intradermal injection for face-lifting.

\section{METHODS}

This was a prospective observational study in which 30 subjects with mild facial skin laxity (grading score of 1-1.5 [13]) and ranging from 20 to 35 years in age were enrolled. To minimize confounding factors, women were excluded from the study if they were pregnant or lactating, had a history of allergy for human albumin or cow's milk protein [14], had an underlying neuromuscular disease, such as atrophy or weakness of palmar muscle, myasthenia gravis or amyotrophic lateral sclerosis or had received BoNT/A injections or undergone other cosmetic procedures in the preceding 12 months.

One hour before starting the procedure, a topical anesthetic cream with 5\% lidocaine and prilocaine (Racser ${ }^{\circledR}$; Galentic Pharma Pvt. Ltd.) was applied onto each subject's face. After the topical anesthetic cream had been removed, all subjects were treated with $\mathrm{ABO}$ (Dysport ${ }^{\circledR}$; Ipsen Biopharm Ltd.) [14] at a dilution of 1 vial:7 mL NSS (i.e. a vial of $500 \mathrm{U}$ of $\mathrm{ABO}$ was reconstituted with $7 \mathrm{~mL}$ of sterile, preservativefree NSS) by a well-trained practitioner using an intradermal injection technique with a 1-cc syringe and a $31-G$ needle. The injection sites, which covered the areas of the upper, mid, lower face and neck, were described in our previous study [12]. All subjects were asked to avoid sauna use, laser or energy-based device treatments and facial massage for 2 weeks after the injections to avoid unwanted diffusion of toxin.

A two- and three-dimensional imaging system (Vectra H1; Canfield Scientific, Inc., Fairfield, NJ, USA) was used for photographic documentation, with identical camera settings, lighting, and patient positioning, at baseline, immediately after injection and during followup at 2 weeks and at 1, 2, 3, 4, 5 and 6 months after treatment. Independent clinical assessments of the face-lifting procedure were conducted by two blinded dermatologists who evaluated comparative two-dimensional photographs taken at the end of the study using a quartile grading scale $(-1=$ worse, $0=$ no improvement, $\quad 1=1-25 \% \quad$ improvement, $2=26-50 \%$ improvement, $3=51-75$ improvement and $4=76-100 \%$ improvement) .

Three-dimensional photographs were also used to quantify changes in the facial volume of the nasolabial fold and jawline. The area of interest was demarcated as that formed by an imaginary line from the alar nasal sulcus to the lower end of nasolabial fold and at the level of the ear lobule to the angle of mandible along the jawline and up towards the midface, respectively. Subjects were also asked to rate the face lifting effects at every visit by using the quartile grading scale mentioned avove. Side effects were also assessed at the end of the study.

The differences in skin laxity and facial volume changes, based on the evaluations of the two- and three-dimensional photographs, were compared between baseline and each follow-up visit. The one-sample $t$ test was used to assess mean changes in volume measurements at each follow-up visit compared to baseline. All data were analyzed using SPSS version 24.0 statistical software (IBM Corp., Armonk, NY, USA). $P$ values of $<0.005$ were considered to indicate statistical significance.

This study was approved by the ethical committee on research involving human subjects of Siriraj institutional Review Board, Faculty of Medicine, Siriraj Hospital, Mahidol University. All procedures performed in studies involving human participants were in accordance with the ethical standards of the institutional and/or national research committee and with the 1964 Helsinki declaration and its later amendments or comparable ethical standards. Informed consent was obtained from all individual participants included in the study. Informed consent was also obtained for publication of the patient images.

\section{RESULTS}

Of the 30 subjects, 28 (93.3\%) completed treatment and attended every follow-up visit. All subjects were female with Fitzpatrick skin 
type II to IV. The average age of subjects was $27.6 \pm 3.4$ (range 22-34) years. The total units of $\mathrm{ABO}$ used varied for each subject, ranging from 200 to $250 \mathrm{U}$, with the average ( \pm standard deviation) dose being $237 \pm 19$ U. When using an onabotulinumtoxin A (ONA):ABO conversion factor of 1:2.5 [15], the comparative dose of ONA used in this study was $94 \pm 7 \mathrm{U}$ (range $80-100 \mathrm{U})$. On a scale of $1-10$, the average pain score from injection was rated as $5 \pm 1$ (range 2-8).

The percentage of subjects reporting facelifting (improvement) was 100.0 immediately after injection, 96.9 at 2 weeks after injection and 96.6, 100.0, 96.6, 44.8, 34.5 and 6.9 at the 1-, 2-, 3-, 4-, 5- and 6-month follow-ups after injection, respectively (Fig. 1). At 3 months after treatment, 37.9 and $6.9 \%$ of the subjects rated themselves to have $51-75 \%$ and $76-100 \%$ improvement of skin laxity, respectively. However, the assessment of face-lifting by dermatologists was lower than that of each patient's evaluation, with the dermatologists assessing improvement in $55.2 \%$ of subjects immediately after injections, in $79.3 \%$ at 2 weeks after injection and in 79.3, 55.2, 31.0, 20.0, 10.0, and $3.3 \%$ at the 1-, 2-, 3-, 4-, 5- and 6-month followups after injections, respectively (Fig. 2). At 3 months after treatment, none of the subjects were rated to have a more than 50\% improvement. The clinical improvement of skin laxity of a representative upatient is shown in Fig. 3.

Three-dimensional photographic analysis was used to detect facial volume changes after treatment (Fig. 4). The change in facial contouring volume of the nasolabial fold (Fig. 5; Table 1) and jawline (Fig. 6; Table 2), as measured by the Vectra H1 imaging system, showed statistically significant differences up to 3 months after injection compared with baseline ( $p=0.001$ and $p=0.001$, respectively). Of note, in Fig. 5, which illustrates the mean volume differences of the nasolabial fold, the value shown at the 5-month follow-up was not considered to be statistically significant (two-tailed $p$ value 0.067 ).

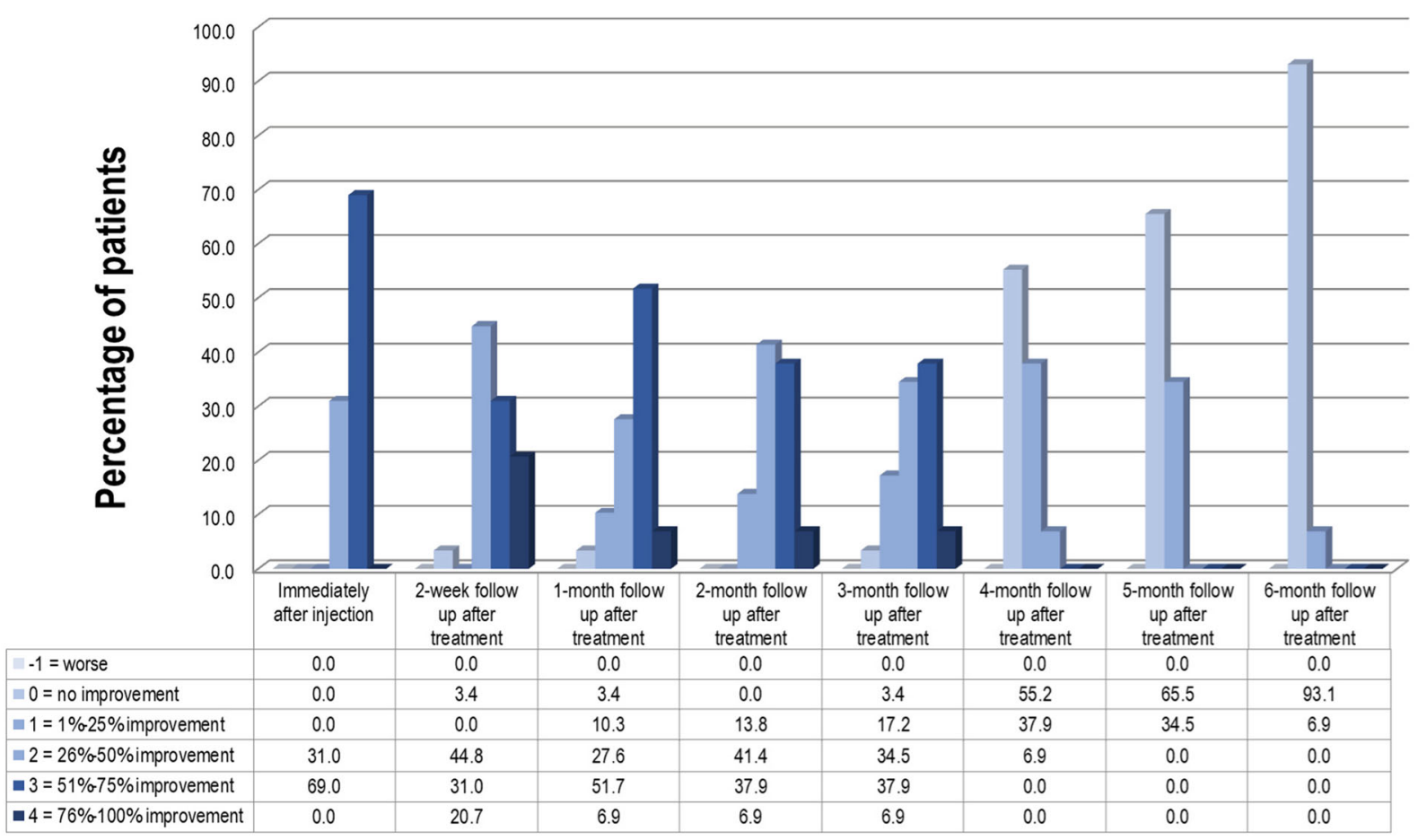

Fig. 1 Subjects' evaluation of face-lifting 


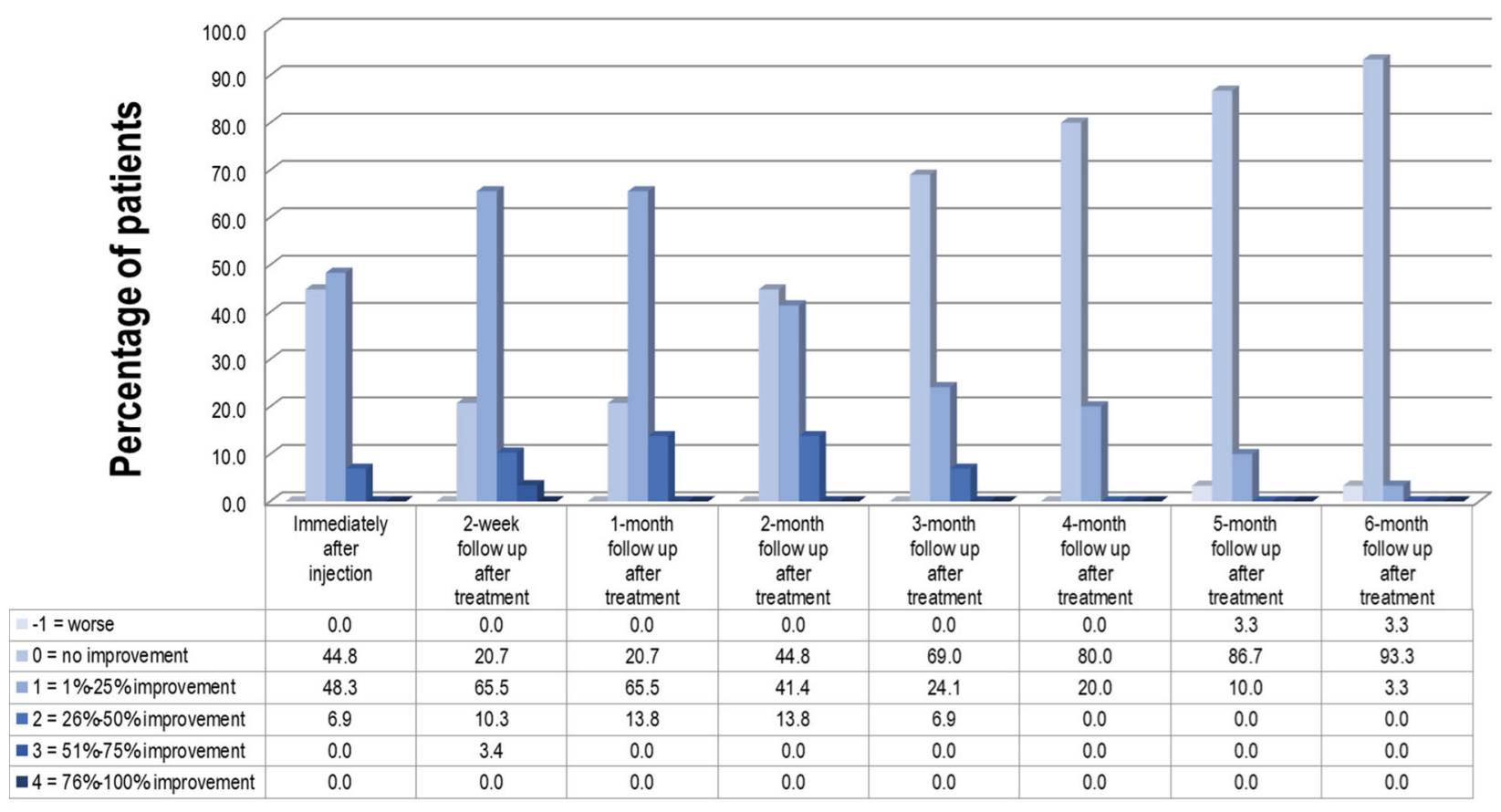

Fig. 2 Physicians' evaluation of face-lifting

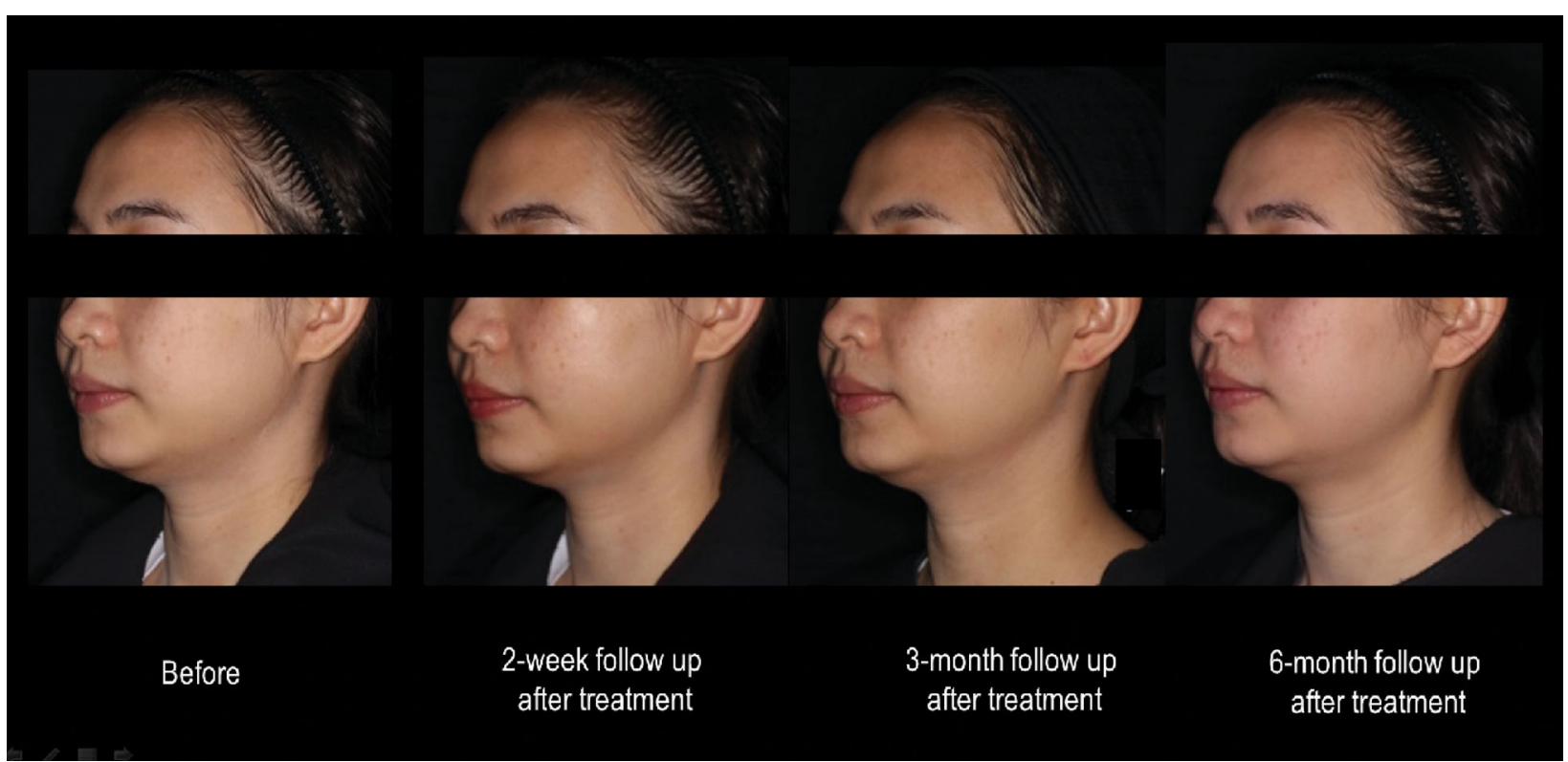

Fig. 3 Clinical improvement of skin laxity of a representative case at 2 weeks and 3 and 6 months after treatment

None of the subjects experienced severe adverse effects, such as allergic reactions, facial palsy, severe paralysis of muscles adjacent to the point of injection or facial asymmetry, both at rest and during facial expression. The only side effect found among the subjects study was minimal bruising, which was found in $13.8 \%$ of subjects. 


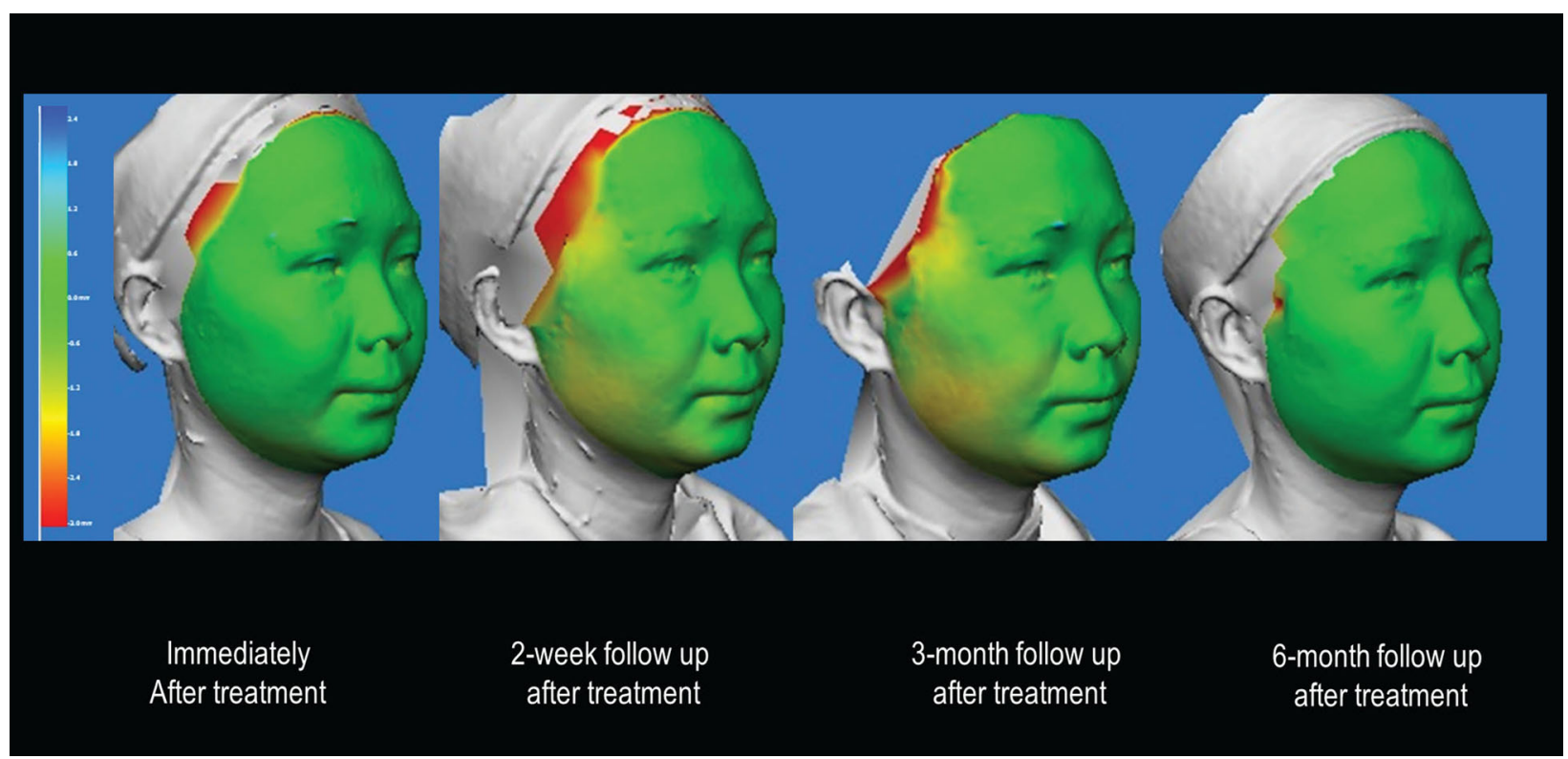

Fig. 4 Vectra $\mathrm{H} 1$ images of a representative case showing volume differences at 2 weeks and 3 and 6 months after treatment. The yellow areas at the 2-week and 3-month follow-ups indicate areas of volume loss or lifting. It is notable that the volume changes are no longer observed at the 6-month follow-up

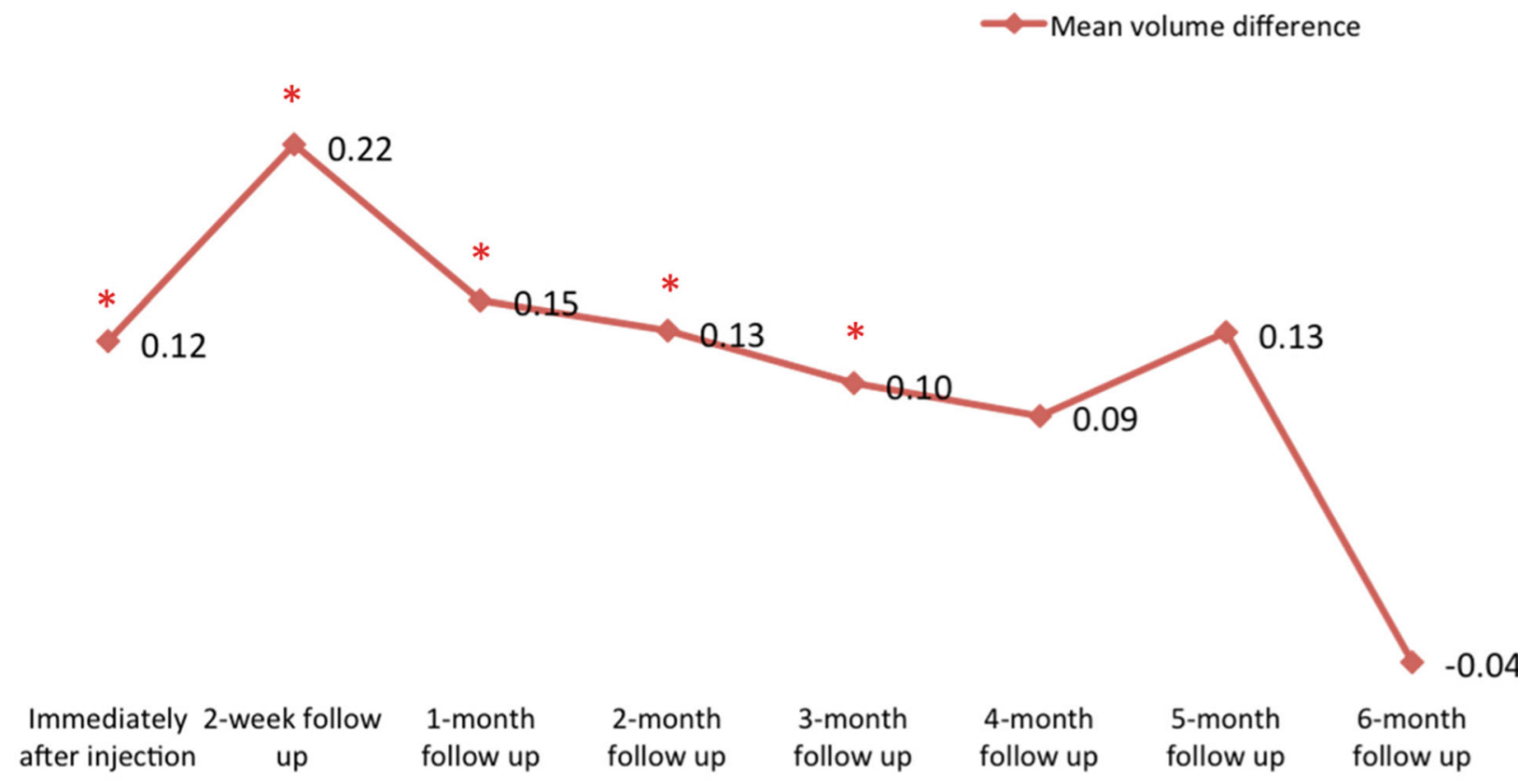

Fig. 5 The average volume difference of nasolabial fold immediately after injection, 2 weeks after injection and at $1,2,3,4,5$ and 6 months after treatment using the one-

sample $t$ test and an adjusted $P$ value of 0.005 . The red asterisk indicates statistically significant values compared with baseline 
Table 1 Vectra analysis of mean volume of nasolabial fold

\begin{tabular}{lcll}
\hline Time point & Mean volume difference & Standard deviation & $P$ value \\
\hline Immediately after injection & 0.12 & 0.17 & 0.000 \\
2-Week follow-up after treatment & 0.22 & 0.41 & 0.000 \\
1-Month follow-up after treatment & 0.15 & 0.15 & 0.000 \\
2-Month follow-up after treatment & 0.13 & 0.10 & 0.000 \\
3-Month follow-up after treatment & 0.10 & 0.10 & 0.000 \\
4-Month follow-up after treatment & 0.09 & 0.44 & 0.140 \\
5-Month follow-up after treatment & 0.13 & 0.52 & 0.067 \\
6-Month follow-up after treatment & -0.04 & 0.42 & 0.521 \\
\hline
\end{tabular}

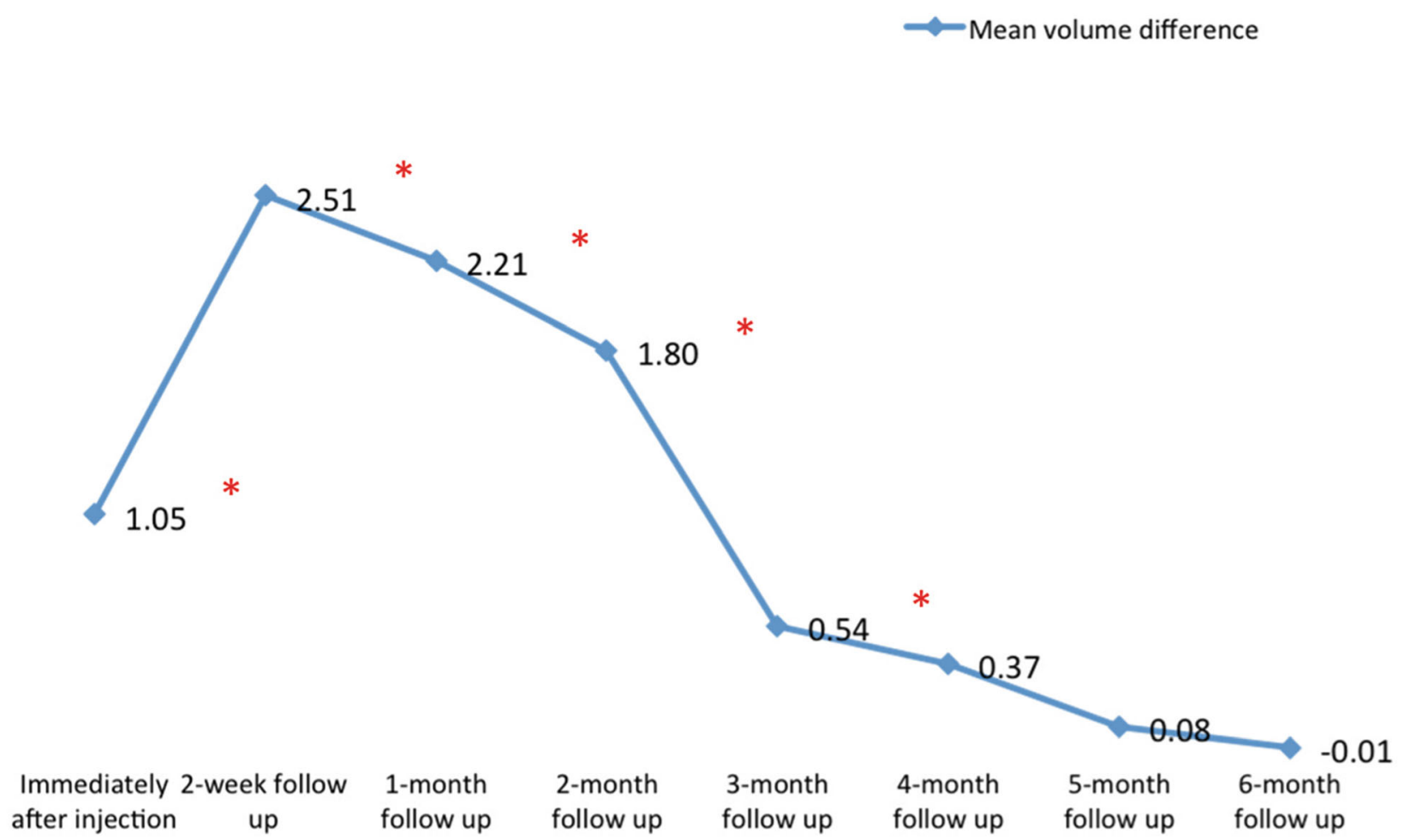

Fig. 6 The average volume difference of jawline immediately after injection, 2 weeks after injection and at 1, 2, 3, 4, 5 and 6 months after treatment using the one-sample $t$ test

\section{DISCUSSION}

Since its first cosmetic indication 30 years ago, an increasing number of practitioners have and an adjusted $P$ value of 0.005 . The red asterisk indicates statistically significant values compared with baseline

conducted studies on BoNT/A, with the result that its use has been expanded to facial regions other than the upper face for rejuvenation purposes [2]. A number of clinical studies have been carried out in the past decade on the 
Table 2 Vectra analysis of jawline

\begin{tabular}{lcll}
\hline Time point & Mean volume difference & Standard deviation & $\boldsymbol{P}$ value \\
\hline Immediately after injection & 1.05 & 0.83 & 0.000 \\
2-Week follow-up after treatment & 2.51 & 1.23 & 0.000 \\
1-Month follow-up after treatment & 2.21 & 1.10 & 0.000 \\
2-Month follow-up after treatment & 1.80 & 1.45 & 0.000 \\
3-Month follow-up after treatment & 0.54 & 0.43 & 0.000 \\
4-Month follow-up after treatment & 0.37 & 1.75 & 0.117 \\
5-Month follow-up after treatment & 0.08 & 1.70 & 0.716 \\
6-Month follow-up after treatment & -0.01 & 1.50 & 0.955 \\
\hline
\end{tabular}

intradermal injection technique for face-lifting that have shown promising cosmetic results; however, very few split-face studies have been conducted that have compared the longevity of the effects of BoNT/A injection vis-à-vis the traditional intramuscular technique. Sapra et al. [11] reported a significant midface lift after intradermal injection of either ONA or ABO at 2 weeks following treatment, which was not observed on the sides treated using the intramuscular technique. Conversely, Jun et al. [9] reported a slightly longer duration of effect on the intramuscular side versus the intradermal side for the treatment of facial wrinkles.

The intradermal BoNT/A injection technique for face-lifting has been widely discussed in the past decade as it offers a more easily accessible and less capital-intensive alternative and/or adjunct to other non-invasive modalities for facial rejuvenation, such as lasers and energybased devices [16]. However, its mechanism of action has previously been in question as some authors of prior studies claim that the face-lifting effects could be from the stimulation of collagen synthesis due to from the multiple injection points involved in the technique (similar to dermal needling) [17-19], whereas the immediate effects observed could merely be secondary to swelling and volume effects of the solution injected [12]. In another of our previous studies however, we were able to prove that the visible tissue lifting was actually a result of an induction of fibroblast contraction, with each BoNT/A product producing contraction to a different extent and at a different speed that was dependent on the dilution used [20]. In particular, the best efficacy of $\mathrm{ABO}$ was seen at a dilution of 1 vial:7 mL NSS, with significant fibroblast cell shortening peaking at $10-12 \mathrm{~h}$ post-injection [20].

The main disadvantage of the intradermal BoNT/A injection technique for face-lifting is that physicians need to be trained on how to deliver the microdroplet injections both consistently and superficially to avoid inadvertently paralyzing the deeper muscle underlying the treated area [16].

In this study, long-term effects were assessed and followed up to 6 months after treatment, with both patient- and physican-rated improvement being statistically significant. It is notable that on the third month after treatment, the majority of subjects still reported that the treatment had made a significant improvement. Similarly, physician raters were still able to observe some sustained effects in $31 \%$ of subjects $(24.1 \%$ with $1-25 \%$ improvement and $6.9 \%$ with $26-50 \%$ improvement) at 3 months after treatment. The discrepancy between each patient's own rating and that of the physicians may be due to the visible lift produced from this technique being very subtle and occurring gradually over time owing to the toxin's effects on fibroblast contraction within the dermis. Previous studies have stated that intramuscular injection has more lasting effects than 
intradermal injections [9]. However, we observed in our study that sustained clinical outcomes can also be achieved up to 3 months using the intradermal injection technique with ABO.

Our previous split-face study on $\mathrm{ABO}$ demonstrated the clinical efficacy of this formulation in face-lifting using the intradermal technique when compared with NSS [12]. Given the split-face design of the previous study, we were unable to determine the duration of effect on the ABO side after the initial 2-week period. The present study shows that given the correct dose, proper technique and good selection of patient, this technique can also produce significant results with lasting effects up to 3 months, similar to the longevity of effects previously reported for the traditional intramuscular technique $[1,2]$.

Our previous study likewise underscored the importance of good patient selection. Subjects who achieved good results were those under the age of 32 years and with an oval face shape. As this was a follow-up study, the authors purposefully excluded subjects older than 35 years to increase the efficacy of this technique [12]. However, the main limitation of this study is its small sample size. A larger patient population will better demonstrate the sustained effects of $\mathrm{ABO}$ at 3 months and even beyond.

\section{CONCLUSION}

In summary, the intradermal injection technique using $\mathrm{ABO}$ at a dilution of 1 vial: $7 \mathrm{~mL}$ NSS provided significant sustained face-lifting effects for up to 3 months post-treatment. Similar to the previous split-face study conducted on the intradermal injection technique for face lifting comparing ABO and NSS, the efficacy of this technique is highly dependent on the skill of the person injecting the formulation, the appropriate dilution and good patient selection.

\section{ACKNOWLEDGEMENTS}

The authors wish to thank Ms. Phassara Klamsawat, Ms. Phonsuk Yamlexnoi, and Mr.
Panyawat Wongjaruwat for their assistance in recruiting subjects and managing the database. Likewise, the authors would like to thank the patient participants for their invaluable contribution to this publication.

Funding. No funding or sponsorship was received for this study or publication of this article. The Rapid Service Fee was funded by the authors.

Authorship. All named authors meet the International Committee of Medical Journal Editors (ICMJE) criteria for authorship for this article, take responsibility for the integrity of the work as a whole, and have given their approval for this version to be published.

Authorship Contributions. Dr. Wanitphakdeedecha had full access to all of the data in the study and takes responsibility for the integrity of data and the accuracy of the data analysis. Study concept and design: Drs. Wanitphakdeedecha. Acquisition of data: Drs. Wanitphakdeedecha, Yan, Apinuntham, and Rojanavanich. Analysis and interpretation of data: Drs. Wanitphakdeedecha, Eimpunth, and Yan. Drafting of the manuscript: Drs. Cembrano and Wanitphakdeedecha. Critical revision of the manuscript for important intellectual content: Dr. Manuskiatti. Statistical analysis: Drs. Yan and Apinuntham. Obtained funding: none. Administrative, technical, or material support: Dr. Manuskiatti. Study supervision: Dr. Manuskiatti.

Disclosures. Rungsima

Wanitphakdeedecha, Chadakan Yan, Chalermkwan Apinuntham, Viboon Rojanavanich, Kathryn Anne G Cembrano, Sasima Eimpunth and Woraphong Manuskiatti have nothing to disclose.

Compliance with Ethics Guidelines. This study was approved by the ethical committee on research involving human subjects of Siriraj institutional Review Board, Faculty of Medicine, Siriraj Hospital, Mahidol University. All procedures performed in studies involving human participants were in accordance with the ethical 
standards of the institutional and/or national research committee and with the 1964 Helsinki declaration and its later amendments or comparable ethical standards. Informed consent was obtained from all individual participants included in the study. Informed consent was also obtained for publication of the patient images.

Data Availability. The datasets during and/ or analyzed during the current study are available from the corresponding author on reasonable request.

Open Access. This article is licensed under a Creative Commons Attribution-NonCommercial 4.0 International License, which permits any non-commercial use, sharing, adaptation, distribution and reproduction in any medium or format, as long as you give appropriate credit to the original author(s) and the source, provide a link to the Creative Commons licence, and indicate if changes were made. The images or other third party material in this article are included in the article's Creative Commons licence, unless indicated otherwise in a credit line to the material. If material is not included in the article's Creative Commons licence and your intended use is not permitted by statutory regulation or exceeds the permitted use, you will need to obtain permission directly from the copyright holder. To view a copy of this licence, visit http://creativecommons.org/licenses/by$\mathrm{nc} / 4.0 /$.

\section{REFERENCES}

1. Satriyasa BK. Botulinum toxin (Botox) A for reducing the appearance of facial wrinkles: a literature review of clinical use and pharmacological aspect. Clin Cosmet Investig Dermatol. 2019;12:223.

2. Cohn JE, Greco TM. Advanced techniques for the use of neurotoxins in non-surgical facial rejuvenation. Aesthet Plast Surg. 2020;1:1-2.

3. Campanati A, Martina E, Giuliodori K, Consales V, Boyr I, Offidani A. Botulinum toxin off-label use in dermatology: a review. Skin Appendage Disord. 2017;3(1):39-56.
4. Small R. Botulinum toxin injection for facial wrinkles. Am Fam Phys. 2014;90(3):168-75.

5. Zhu J, Ji X, Xu Y, et al. The efficacy of intradermal injection of type A botulinum toxin for facial rejuvenation. Dermatol Ther. 2017;30(1):1-4.

6. Petchngaovilai C. Midface lifting with botulinum toxin: intradermal technique. J Cosmet Dermatol. 2009;8(4):312-6.

7. Wu WT. Microbotox of the lower face and neck: evolution of a personal technique and its clinical effects. Plast Reconstr Surg. 2015;136(5 Suppl): 92S-100S.

8. Kim YJ, Lim OK, Choi WJ. Are there differences between intradermal and intramuscular injections of botulinum toxin on the forehead? Dermatol Surg. 2020. https://doi.org/10.1097/DSS. 0000000000002379 .

9. Jun JY, Park JH, Youn CS, Lee JH. Intradermal injection of botulinum toxin: a safer treatment modality for forehead wrinkles. Ann Dermatol. 2018;30(4):458-61.

10. Fabi SG, Sundaram H, Guiha I, Goldman MP. A twocenter, open-label, randomized, split-face study to assess the efficacy and safety of one versus three intradermal injection sites of abobotulinumtoxinA in the treatment of lateral periocular rhytides. J Drugs Dermatol. 2013;12(8):932-7.

11. Sapra P, Demay S, Sapra S, Khanna J, Mraud K, Bonadonna J. A Single-blind, split-face, randomized, pilot study comparing the effects of intradermal and intramuscular injection of two commercially available botulinum toxin a formulas to reduce signs of facial aging. J Clin Aesthet Dermatol. 2017;10(2):34-44.

12. Wanitphakdeedecha $R$, Ungaksornpairote $C$, Kaewkes A, et al. The comparison between intradermal injection of AbobotulinumtoxinA and normal saline for face-lifting: a split-face randomized controlled trial. J Cosmet Dermatol. 2016;15(4): 452-7.

13. Alexiades-Armenakas M. A quantitative and comprehensive grading scale for rhytides, laxity and photoaging. J Drugs Dermatol. 2006;5(8):808-9.

14. US Food and Drug Administration. Dysport ${ }^{\circledR}$ Highlights of prescribing information. https:// www.accessdata.fda.gov/drugsatfda_docs/label/ 2016/125274s107lbl.pdf. Accessed 02 Jun 2020

15. Kashtipour K, Chen JJ, Espay AJ, Mari Z, Ondo W. OnabotulinumtoxinA and AbobotulinumtoxinA dose conversion: a systematic literature review. Mov Disord Clin Pract. 2016;3(2):109-15. 
16. Schlessinger J, Gilbert E, Cohen JL, Kaufman J. New uses of abobotulinumtoxinA in aesthetics. Aesthet Surg J. 2017;37(Suppl 1):S45-S58.

17. Noland ME, Lalonde DH, Yee GL, Rohrich RJ. Current uses of botulinum neurotoxins in plastic surgery. Plast Reconstr Surg. 2016;138(3):519e-e530530.

18. Chang SP, Tsai HH, Chen WY, Lee WR, Chen PL, Tsai TH. The wrinkles soothing effect on the middle and lower face by intradermal injection of botulinum toxin type A. Int J Dermatol. 2008;47(12): 1287-94.
19. Kapoor R, Shome D, Jain V, Dikshit R. Facial rejuvenation after intradermal botulinum toxin: is it really the botulinum toxin or is it the pricks? Dermatol Surg. 2010;36(Suppl 4):2098-105.

20. Wanitphakdeedecha R, Kaewkes A, Ungaksornpairote C, Limsaengurai S, Panich U, Manuskiatti $\mathrm{W}$. The effect of botulinum toxin type A in different dilution on the contraction of fibroblast-in vitro study. J Cosmet Dermatol. 2019;18(5):1215-23. 